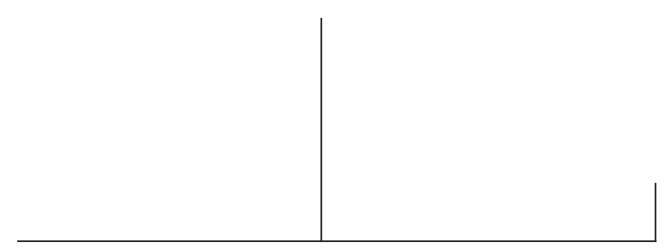

Rev. Latinoam. Psicop. Fund., II, 4, 11-26

\title{
A entrada do chiste na cena analítica
}

\author{
Luciana Balbo
}

O artigo se utiliza do dito espirituoso freudiano para refletir sobre algumas questões do ato analítico. o exemplo clínico apresentado se presta a uma ilustração prática de uma possível estrutura chistosa do ato analítico.

De forma sintética discute-se os pontos de interesse da compreensão freudiana sobre os chistes para uma aproximação da noção de ato analítico. $O$ caso clínico é retomado, com o intuito de funcionar como uma espécie de linha, que vai costurando os aportes teóricos apresentados ao longo do texto. Lacan é mencionado, no sentido de ampliar a visão sobre os chistes e incluir a noção de chiste como um ato de sentido.

Palavras-chave: Psicanálise, chiste, ato analítico, transferência 


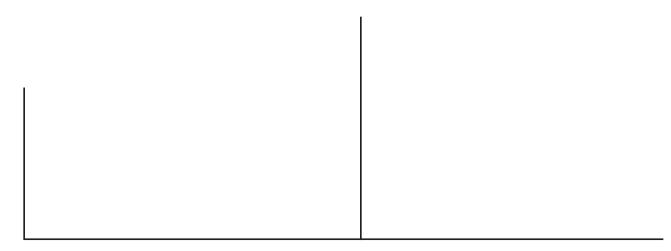

Therefore, since brevity is the soul of wit And tediousness the limbs and outward flourisher

I will be brief.

( Hamlet, Shakespeare) ${ }^{1}$

Este texto pretende expor um corte em algumas idéias teóricas sobre a noção de ato analítico e o interesse em aproximá-las da concepção freudiana sobre os chistes para demonstrar sua pertinência e engenhosidade para $\mathrm{o}$ atendimento clínico.

A via pela qual me proponho a pensar o ato analítico é a do dito espirituoso freudiano. O chiste é utilizado aqui para iluminar o ato analítico, para se pensar em como funciona aquilo que permite a modificação de posição subjetiva do paciente.

Da escolha de se refletir sobre o tema dos chistes e mesmo do humor, segundo uma perspectiva freudiana, passei a imaginar que teria de resignar-me a pensar a sério sobre algo que, precisamente, não parecia sê-lo. Talvez dissertar sobre os chistes fosse confundir o jogo. Será por isso que são tão raros os que trataram clinicamente desse assunto? "Os chistes e sua relação com o inconsciente" é um dos trabalhos de Freud menos citados por psicanalistas.

1. "Já que a brevidade é a alma do engenho/ E o tédio seu corpo e externo ornato/ Serei breve" Shakespeare, W. Hamlet. Porto: Lello \& Irmão Editores, Ato II, cena II, fala de Polonius, p. 94. 


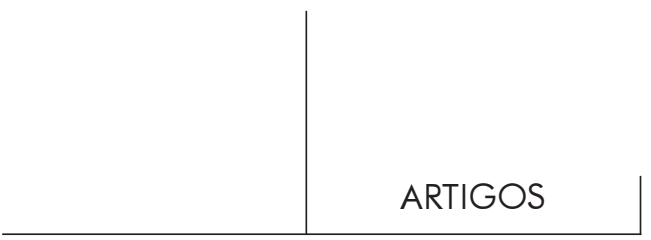

No entanto, quando eu atendia a meus pacientes em bases psicanalíticas, os ditos espirituosos e os trocadilhos pareciam funcionar surpreendentemente para desobstruir caminhos antes difíceis de serem trilhados.

\section{Exemplo clínico como provocação}

\section{Antecedentes}

O paciente que estarei chamando de Carlos veio para tratamento psicanalítico quando contava 19 anos. Sua irmã mais velha é quem procura o atendimento para o irmão, já é formada na universidade e trabalha, uma conhecida sua, psiquiatra, é que faz a indicação de meu nome.

O pai do paciente é quem marca a entrevista inicial e comparece acompanhado de sua esposa, mãe de Carlos, aos primeiros contatos para a análise. Nessas entrevistas com os pais recebo algumas informações interessantes a respeito de Carlos. Notei, antes de mais nada, que toda a sua família havia entrado em contato comigo, direta ou indiretamente (sua irmã nunca veio ao consultório) antes que o próprio paciente pudesse manifestar algum interesse por uma análise. Aspecto que só mais tarde pôde fazer sentido para mim ao longo do trabalho com Carlos.

Carlos é o filho mais novo de uma prole de dois. A diferença de idade entre o paciente e sua irmã é de 5 anos. O paciente teve um desenvolvimento normal até os 8 anos de idade quando começou a apresentar uma disfunção hormonal que acelerou seu desenvolvimento sexual. Com 8, 9 anos possuía já características físicas de um rapaz mais velho (pêlos pelo corpo, inclusive pubianos, crescimento peniano, voz grossa, desenvolvimento precoce de caracteres sexuais secundários).

Freqüentou médicos endocrinologistas que diagnosticaram o problema e o trataram, o paciente teve, portanto, um desenvolvimento físico precoce para as questões da sexualidade. Desenvolvimento este que não pareceu acompanhá-lo para outras áreas de sua vida, sempre foi um aluno fraco, repetindo de ano várias vezes (3), o que se tornou um grande constrangimento para o paciente e seu pai. O pai de Carlos dizia-se muito preocupado com isso pois o filho estava repetindo pela segunda vez o $2^{\circ}$ ano colegial, passava muitas horas trancado em seu quarto ouvindo músicas de Michael Jackson, Madonna e outros. Gastava toda sua mesada comprando vídeos com clipes desses cantores, não saía mais de casa, a não ser para ir à escola e dizia que não tinha mais amigos que valessem a pena.

Nas primeiras entrevistas com o paciente, este dizia não ter o desejo de fazer análise, mas que o faria porque o pai estava mandando, não conseguia manter contato visual com a analista, pouco falava, ficando muito perseguido pela presença do divã. 


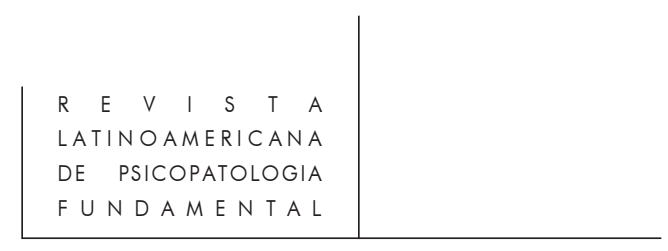

Fazia perguntas do tipo: "Mas pra que serve essa cama aí?!" "Ah... é divã, mas pra mim é cama...", "Não vou deitar aí, não!"

Com muito custo consegui encontrar alguma demanda de análise proveniente do próprio Carlos, que começou a queixar-se de sua dificuldade com garotas. Contou que até então não tinha conseguido ter uma namorada nem manter relacionamentos sexuais. Segundo ele, tinha saído com uma garota umas duas vezes e achou que ela não era honesta, pois queria "ir logo dando pra ele!", mantinha intensos relacionamentos platônicos.

Sobre sua dificuldade na escola, Carlos alegava que não conseguia aprender e que ficava também muito ansioso para fazer provas e trabalhos. Sentia-se perseguido pelos professores que supostamente faziam exigências descabíveis para os trabalhos de casa. Queixava-se de que o pai não permitia que usasse o computador porque gastava horas nos jogos eletrônicos. $\mathrm{O}$ videocassete tinha sido apreendido e ficava escondido num armário a que Carlos não tinha acesso.

Iniciamos os atendimentos e Carlos vinha sempre acompanhado pelo pai, embora viesse dirigindo na estrada, seu pai achava que ele ainda não possuía habilidade para dirigir no movimento da cidade. Realizava duas sessões por semana, sentado.

Durante os primeiros três meses do tratamento Carlos não olhava para a analista e não fechava a porta da sala de espera quando chegava, assim como não fechava as portas da sala de atendimento. Embora bastante surpreendida com o fato, nos primeiros encontros eu me levantava e fechava as portas. Comecei a notar que isso me causava um certo desconforto, Carlos me encarregava de zelar por sua intimidade e privacidade. Ficava como que aturdida e impossibilitada de colocar em palavras o que se passava em nossa relação, uma vez que se assim o fizesse, sem fechar as portas da sala de atendimento, estaria incorrendo numa indiscrição, pois seu pai ouviria da sala de espera boa parte de nossa conversa. Além disso, Carlos mantinha-se na maior parte do tempo calado ou monossilábico como se aquilo não lhe dissesse respeito. Percebia que estávamos num impasse. Durante muitos desses atendimentos, logo depois que me via impelida a fechar as portas, eu passava, pelo menos os 10 primeiros minutos do contato com Carlos, tendo de digerir uma sensação muito forte de confusão e desconforto, não me sentindo completamente livre para estar com ele.

Cena 1

Num desses dias, Carlos deixa a porta da sala de atendimento tão aberta que era possível para a analista ver o pai do paciente sentado na sala de espera, lendo. Logo após a entrada do paciente na sala, a analista diz: "Já entraram todos?" o paciente olha bem dentro dos olhos da analista, ri e imediatamente fecha as portas 


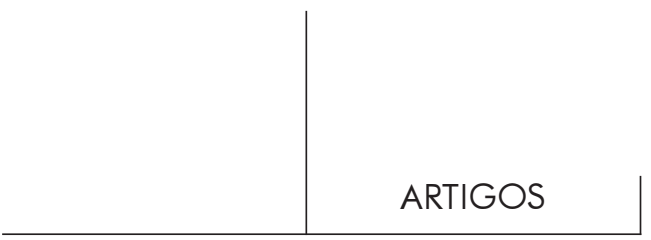

duplas da sala de atendimento. Encostando na porta, diz: "Melhor deixar meu pai esperando lá fora". Pela primeira vez, em meses, é capaz de fazer associações livres, falando durante a maior parte do atendimento. Tanto a porta da sala de espera do consultório, como as da sala de atendimento, sempre foram hermeticamente fechadas a partir de então.

Fiquei muito surpresa que Carlos pudesse ter tido uma compreensão tão aguda da situação. Percebi, imediatamente, que ele me oferecia um lugar, muitas vezes, ocupado por seu pai de acreditar que ele não possuía muitas condições intelectuais e emocionais para a vida. A forma como os contatos iniciais para a análise foram feitos tomou um outro sentido para mim. Tive de experimentar na pele, junto com Carlos, como ele estava sempre acompanhado de todos esses entes familiares de modo que sua personalidade não parecia ter integrado essas figuras em algo ou alguém que ele pudesse chamar de ele mesmo. Carlos deixava a porta aberta para que a analista, em seu lugar, se incomodasse com todas essas pessoas invadindo sua sessão psicanalítica. Estabelecia uma transferência em que a analista, assim como aqueles objetos invasores e externos ao paciente, funcionavam como uma extensão de seu desejo narcísico. Em sessões posteriores menciona o fato de se sentir sempre muito perseguido pelo pai, mas que manter a porta fechada o estava ajudando muito. Pôde também, à medida que mantinha a porta do consultório fechada, começar a sair de seu quarto e assistir a alguns programas de televisão com a família e procurar antigos amigos para escutarem músicas juntos. Conseguia notar que as figuras meio andróginas de Michael Jackson e Madonna é que lhe interessavam. Seu desenvolvimento físico precoce começava a aparecer como um inibidor de seu desenvolvimento emocional para as questões da sexualidade. Sua precocidade fisiológica da sexualidade e a dissimetria emocional que isso causou, deixava-lhe curioso sobre figuras que contivessem uma conotação de masculino e feminino meio nebulosas, assim como ser um adulto homem, ou mulher, era algo nebuloso para Carlos. Ele passou a notar que ficava pensando fixamente em suas paixões platônicas quando ia à escola e que provavelmente não ia bem porque não conseguia estar "inteiro" nas aulas, suas portas estavam sempre "abertas" para essas fantasias que não lhe permitiam manter um contato mais adequado com a realidade externa e também com sua analista. Qualquer recusa ou frustração pessoal funcionavam como um sério inibidor para seu desenvolvimento intelectual.

Acredito que a vinheta clínica ajude a visualizar melhor onde o desejo pode chegar permitindo abarcar não só o campo analítico em questão, como também, delimitando a área de discussão para este texto. A vinheta clínica não deve ser entendida de outra forma que não a de uma primeira ilustração para que o leitor possa visualizar mais claramente o que chamo de ato analítico. Em momento algum se pensa em dissecar o caso clínico, nem mesmo fazer uma análise profunda da 


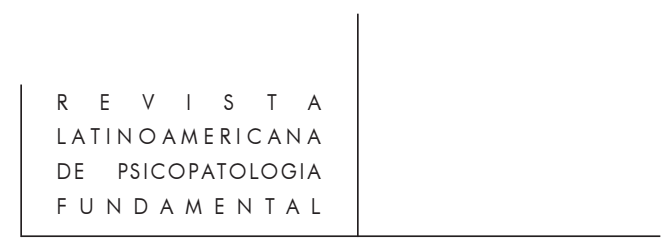

transferência, tão necessária para o entendimento do caso, mas desnecessária para a discussão teórica que se pretende com a ilustração.

\section{Considerações teóricas iniciais}

Segundo Pierre Fédida ${ }^{2}$ o estabelecimento do setting analítico e o enquadre adequado do paciente na situação analítica permitem ao psicanalista criar um espaço razoavelmente estável no qual lhe seja possível pensar as questões de seu paciente sem ser diretamente confrontado com a irrupção violenta dos afetos do paciente e seus próprios.

No entanto, quando a instauração do setting analítico é perturbada ou momentaneamente destruída, o analista se vê confrontado com uma situação de angústia vivida por ele e, também, por seu paciente que dificulta a tradução em palavras de tudo o que pode ser experimentado no tratamento. A função analítica fica automaticamente interrompida.

Naturalmente que eu me via envolvida com as questões do setting analítico na relação com Carlos, percebia claramente que precisava do setting para me proteger de um contato mais próximo com ele e para preservar minha própria criatividade analítica. Assim como Carlos, eu me aferroava à idéia de um setting ideal em que nada sairia fora de lugar, qualquer movimento me deixava, talvez, tão "emburrecida" como ele nas aulas. Aprendi que o setting funciona muito mais na mente do analista, na capacidade do analista de sustentar a associação-livre, a transferência e a atenção livremente flutuante, do que em aspectos concretos como sala, horários, divã etc. Como diria Jean Laplanche ${ }^{3}$, é a situação analítica que deve ser preservada na relação com o paciente.

Trabalho com a idéia de que o ato analítico reinstaura uma dimensão simbólica que com o agir não seria possível. Essa dimensão simbólica introduz a marcação de um sentido, também simbólico, na relação analítica. Tento, com a vinheta clínica, mostrar o ato analítico operando na relação analítica e buscar a estrutura de chiste do ato analítico.

A reflexão de um efeito de chiste na estrutura do ato analítico não quer dizer que uma pontuação ou interpretação ao paciente deva ser sempre chistosa ou engraçada, na verdade, o que importa é que a colocação ao paciente possua uma estrutura de chiste, o que já seria suficiente para produzir o efeito de desconcerto e esclarecimento interessante para movimentar a cena analítica. Essa dimensão de chiste permitiria também observar que, na relação analítica, tanto o paciente quanto

2. P. Fédida. Clínica psicanalítica. Estudos. São Paulo: Escuta, 1988.

3. J. Laplanche. Problemática V-A Tina - A transcendência da transferência. São Paulo: Martins Fontes, 1993. 


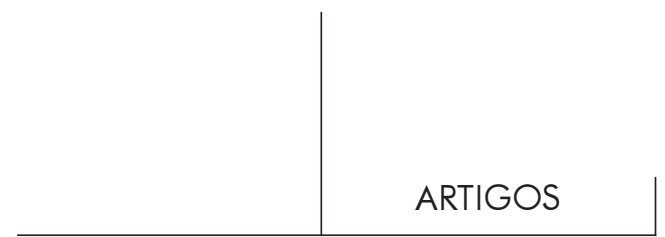

seu analista são surpreendidos pela descoberta do inconsciente do paciente. $\mathrm{O}$ analista não estaria à frente de seu paciente podendo antever o que viria dos movimentos inconscientes deste, estariam juntos, sendo tomados, invadidos, pelo aparecimento do inconsciente. Aquilo que aparecia na relação analítica como algo cristalizado e rígido fica então aberto para novas possibilidades de significações inconscientes, novas possibilidades significantes.

Naturalmente não proponho que o chiste deva fazer parte de toda estrutura do ato analítico como se o mesmo desse conta de esgotar integralmente a idéia de ato. O chiste é a forma como faz sentido para mim ampliar a concepção de ato analítico e evidenciar alguns elementos fundamentais de sua estrutura. Há de haver outras.

No momento em que faço a pontuação anteriormente descrita na vinheta clínica, não possuo muita noção do que poderia estar atingindo do inconsciente de Carlos com minha colocação. Ela me ocorre como ocorrem os chistes e só posteriormente, fora da sessão, consigo apreender o que se passou comigo e com Carlos naqueles momentos. Experimentamos uma espécie de alívio na sessão, diferente para cada um de nós, que nos permitiu uma aproximação analítica. Eu, como analista, sinalizo a existência de um lugar de suposto saber sem ocupá-lo e Carlos, por sua vez, encontra alguém que deve saber dele mais do que ele próprio, mas que pode falar sua língua.

A hipótese de uma estrutura de chiste no ato analítico nos permitiria, ainda, questionar a clínica psicanalítica como possuidora de respostas definitivas para as questões de seu paciente. Como se pensar a clínica a partir desse resto que sempre sobra e do qual o chiste magistralmente nos dá notícias?

Mais do que propor que um analista faça chistes com seu paciente é a partir dessa situação clínica que eu posso pensar o ato psicanalítico dentro de diretrizes propriamente metapsicológicas, talvez levando em conta a idéia de Ferenczi ${ }^{4}$ sobre uma metapsicologia da clínica psicanalítica. O chiste me dá uma referência fecunda sobre a qual eu penso o ato psicanalítico metapsicologicamente.

\section{Os chistes}

No prefácio do livro dos chistes, James Strachey ${ }^{5}$ (1905) nos faz uma interessante preleção da razão subjetiva de Freud para dedicar-se ao problema dos chistes. Era o fato de que seu amigo Fliess com quem, nessa época, Freud ainda

4. S. Ferenczi. O diário clínico. São Paulo: Martins Fontes, 1990.

5. S. Freud (1905). "Os chistes e sua relação com o inconsciente". ESB, vol. VIII. Rio de Janeiro: Imago, 1988. 


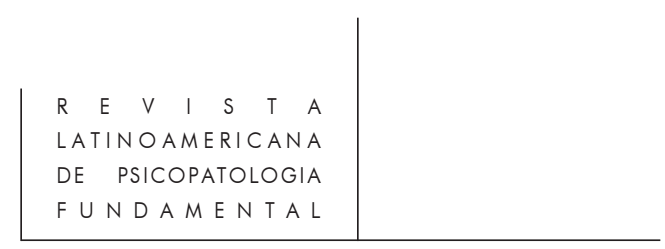

mantinha uma intensa correspondência, havia se queixado de que os sonhos estavam por demais cheios de chistes. Comentou isso ao ler as primeiras provas de $A$ interpretação dos sonhos em 1899.

Esse episódio funcionou como uma espécie de detonador do interesse de Freud pelo assunto, embora ele já houvesse se referido no próprio $A$ interpretação dos sonhos a um mecanismo de efeitos cômicos. Na história clínica de Fräulein Elizabeth von R., encontrada em "Estudos sobre a histeria" (1895), Freud menciona, em uma nota de rodapé, um trocadilho existente no sonho de outra de suas pacientes Fräu Cäcilie M. Seu interesse, portanto, remontava a uma época muito anterior a que o livro dos chistes fora escrito.

Mas curiosamente o livro dos chistes não teve tanta atenção de Freud quanto os outros publicados nessa mesma época, tanto $A$ interpretação dos sonhos quanto "Psicopatologia da vida cotidiana" e também em "Três ensaios sobre a sexualidade" foram revistos, expandidos e modificados. O mesmo não se deu com o livro dos chistes, apenas alguns pequenos acréscimos foram realizados para a segunda edição e, depois, não foi mais tocado.

Além de ser um dos livros de Freud menos citado, "Os chistes e sua relação com o inconsciente" parece ter-se mantido à parte de todos os outros escritos de Freud. Vinte e dois anos depois Freud retoma o fio da meada e nos brinda com "O humor" de 1927, na tentativa de lançar luz sobre um assunto que ainda lhe parecia obscuro. Esse texto se apresenta como um breve artigo, já discorrendo sobre o humor numa perspectiva da, então, recente proposta de concepção de mente introduzida no texto "O ego e o id" de 1923.

Naturalmente o livro dos chistes, mais do que todos os outros livros de Freud, apresenta-se como um grande problema para os tradutores; uma vez que muitos dos chistes citados no livro só fazem sentido em alemão, ou perdem sua sutileza e espirituosidade porque envolvem algum jogo de palavras intraduzível. Ainda assim, com este trabalho, espera-se poder recuperar, senão completamente, pelo menos parte da engenhosidade e astúcia do trabalho dos chistes para que se possa fazer ligações de sua estrutura com o ato analítico.

Os chistes podem ser definidos como "habilidade de encontrar similaridades em coisas dessemelhantes", "descobrir similaridades escondidas", "habilidade de fundir várias idéias, diversas umas das outras", "um contraste de idéias", "sentido no nonsense", "desconcerto e esclarecimento", "conexão de duas idéias que de algum modo contrastam entre si". Essas são as definições citadas por Freud ${ }^{6}$ (1905) dos vários autores que ele já havia lido na época e que discorriam sobre os chistes.

6. S. Freud (1905). Op. cit., pp. 18-19. 


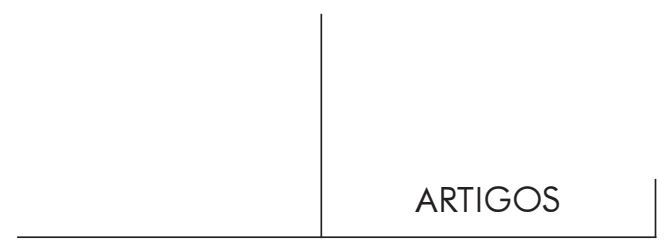

Lipps, Fischer e Heymans estavam muito mais preocupados em descobrir os efeitos cômicos dos chistes. Freud não se ocupou disso. No entanto, ele próprio propõe uma definição, no mínimo curiosa, de que chistes seriam aquilo que determinamos que sejam chistes.

Freud estava mais ocupado em se perguntar o que fazia de um dito algo espirituoso. Possuía duas respostas para essa questão: ou era algo da ordem do pensamento (conteúdo) ou era algo da ordem da expressão (forma). Freud acabou por se dar conta de que o específico de um chiste está muito mais ligado à sua forma e expressão, do que ao pensamento. E talvez seja por esse caminho que se pode ligar o chiste ao ato analítico.

O chiste acaba sendo magistral para falar de algo que não pode ser dito, não pode aparecer como tal. O elemento fundamental do chiste é a questão do jogo, embora o jogo de palavras seja suportado por uma intencionalidade subjetiva que não é da ordem da consciência. Os chistes possuem um elemento que se transmite; tanto quem faz o chiste quanto quem o ouve é surpreendido pelo que é transmitido pelo chiste.

Um conceito precisa corresponder a um significante para estabelecer um sentido. É assim, pelo menos, que a análise do discurso define a noção de sentido. No entanto, o que se observa no famoso chiste de Heine, citado por Freud (1905) sobre o comentário de Hirsch-Hyacinth, é que não há correspondência entre o significante e o significado. Trata-se do significante "familionariamente".

$\mathrm{O}$ significante familiar não corresponde ao significado milionário. E, ainda assim, o chiste passa a mensagem, provoca um efeito de significação. Talvez não da ordem de uma comunicação comum, mas sim de uma linguagem inconsciente.

Ocorre uma preponderância do significante que produz um efeito de sentido, um sentido inconsciente. $\mathrm{O}$ chiste veicula um sentido inconsciente. O conteúdo é sempre efeito do material, como diria Lacan $^{7}$, subvertendo a noção mais clássica de sentido dada por Saussure. Essa nova noção de sentido, no mínimo, balança as estruturas da concepção de que a um significante corresponde um significado, como estabelecido pelas teorias da comunicação. O sentido está num lugar da mente e a linguagem serve para revestir esse sentido para que esse possa ser comunicado ao outro.

O chiste mostra que quando se diz alguma coisa se diz também outra. Se diz algo que não poderia ser dito pela censura da consciência. Pode-se até pensar que não existe uma linguagem consciente, a linguagem é a dos equívocos, dos lapsos, dos trocadilhos nos quais aparece uma outra dimensão daquilo que não foi 


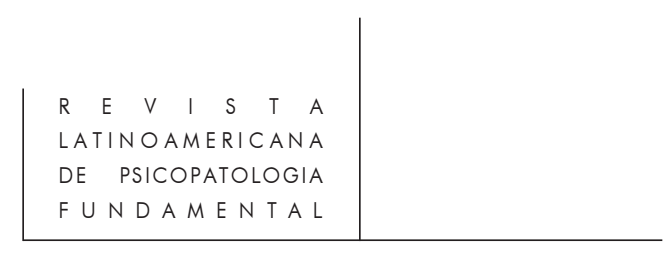

conscientemente dito, mas que está presente. É essa dimensão por onde se faz interessante aproximar o chiste da noção de ato psicanalítico.

Freud encontra algumas características comuns do chiste: a brevidade, a condensação, o deslocamento. Ao estudar essas questões subjetivas dos chistes, ele acaba por relacioná-los com os sonhos. Nota que a brevidade do chiste não é uma brevidade qualquer. A particular brevidade dos chistes está ligada à formação de um substituto - condensação. Assim como os sonhos, os chistes fazem parte de um processo psíquico de funcionamento normal.

Em A interpretação dos sonhos, texto de 1900, temos: o conteúdo manifesto do sonho; o conteúdo latente do sonho; o trabalho de elaboração onírica (formação do sonho); a análise interpretativa do sonho. Nesse sentido, Freud faz uma analogia do trabalho dos sonhos com o dos chistes. Estabelece essas mesmas etapas para a formação de um chiste a partir do trabalho da condensação e do deslocamento que implica uma deformação do conteúdo manifesto do chiste.

O chiste, assim como o sonho, pressupõe um outro para quem se conta o assunto. O chiste é feito do material lingüístico enquanto o sonho é mais trabalhado em forma de imagens (figurabilidade), embora o sonho possa também ser sonhado em forma de palavras. Aqui pode-se fazer uma ligação com o inconsciente estruturado como uma linguagem de Lacan e pode-se, ainda, pensar o chiste como uma formação do inconsciente. O chiste estaria, dessa forma, assentado na língua. Para Lacan, o sonho naquilo de sua estrutura é também uma linguagem.

Seguindo mais, passo a passo, as colocações de Freud sobre os chistes encontramos a idéia de que a atividade chistosa tem o propósito inequívoco de suscitar prazer em seus ouvintes. Também o chiste é uma atividade que visa derivar prazer dos processos mentais, sejam intelectuais ou de outra espécie.

Falando de modo geral, um chiste requer três pessoas: além da que faz o chiste, deve haver uma segunda que é tomada como objeto da agressividade hostil ou sexual e uma terceira na qual se cumpre o objetivo do chiste de produzir prazer.

Vamos ater-nos ao fato de que isso comprova, a saber, que não é a pessoa que faz o chiste que ri dele, desfrutando portanto de seu efeito deleitoso, mas o ouvinte inativo. Isso se torna um aspecto de suma importância para a clínica psicanalítica, uma vez que o analista pode utilizar a estrutura de chiste para atingir seu paciente e conseguir liberar aspectos conflitivos, ludibriando a censura, para tornar possível a motilidade desses impulsos que estariam relegados, na melhor das hipóteses, a vir à tona em forma de atos falhos, sintomas etc.

$\mathrm{O}$ chiste recupera um gozo que ficou impedido pelo recalque. Todo o tempo Freud nos relembra da dificuldade do sujeito em abrir mão de uma via de descarga prazerosa, o chiste parece conseguir recuperar parte dessa satisfação ligada ao recalque. Freud é, na verdade, muito cauteloso com esta questão do prazer recuperado pelo chiste. Ele nos coloca que o efeito do chiste no sujeito é enganoso. 


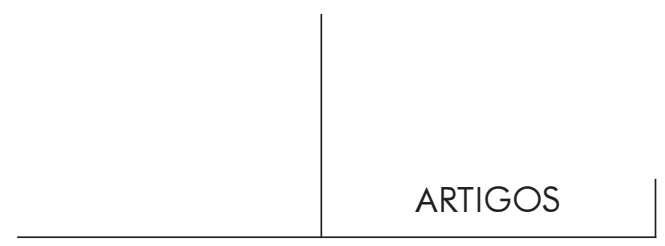

No chiste inocente o prazer advém somente da técnica, no entanto, já o prazer do chiste tendencioso está ligado tanto à técnica quanto à tendência do chiste. $\mathrm{O}$ chiste recupera o prazer com o jogo de palavras para recuperar um jogo de significantes.

O prazer em um chiste emerge de um tal "curto circuito" que parece ser também maior quanto mais diferentes sejam os dois círculos de idéias conectados pela mesma palavra - quanto mais longe estejam, maior é a economia que o método técnico do chiste fornece ao curso do pensamento. Podemos notar também aqui que os chistes estão utilizando um método de conexão das coisas, rejeitado e cuidadosamente evitado pelo pensamento sério. Algo de familiar é descoberto onde poderíamos, pelo contrário, esperar algo de novo. A redescoberta do que é familiar ${ }^{8}$ é gratificante e mais uma vez não nos é difícil reconhecer esse prazer obtido pela economia relacionando-o à economia na despesa psíquica.

Mas é interessante também fazer uma investigação da determinação subjetiva dos chistes porque é uma experiência geralmente reconhecida de que ninguém se contenta em fazer um chiste apenas para si próprio. Um impulso de contar o chiste a alguém está inexoravelmente ligado à elaboração do chiste. Se alguém acha alguma coisa cômica, pode divertir-se consigo mesmo. Um chiste, ao contrário, deve ser contado para alguém mais. O processo psíquico da construção de um chiste não parece terminado quando o chiste ocorre a alguém: permanece algo que procura, pela comunicação da idéia, levar o desconhecido processo de construção do chiste a uma conclusão.

Segundo Laplanche ${ }^{9}$, os significantes que estão no inconsciente, apesar de terem perdido a referência (relação com um significado), conservam o valor comunicativo que possuíam. É um significante que comunica apenas a vontade de comunicar de modo que o inconsciente se endereça a alguém.

Não é possível determinar qual é a base do impulso de comunicar um chiste, mas pode-se constatar outra peculiaridade do chiste: se encontro algo cômico, posso rir gostosamente, embora seja verdade que também me satisfaço se posso fazer alguém mais rir, contando-lhe o fato. Mas não posso rir de um chiste que me tenha ocorrido, ou que eu tenha inventado, a despeito do inequívoco prazer que o chiste me dá. É possível que a minha necessidade de comunicar o chiste esteja ligada à gargalhada que este produz, gargalhada esta que me é negada, mas que se manifesta em outra pessoa. E talvez possua também relação com o impulso de comunicar algo a alguém a respeito do meu inconsciente. A função da comunicação, portanto, é efeito do encontro com o Outro. Fica claro que depende de alguém, mas alguém que diga o que o sujeito disse, função que não poderia ser cumprida se não estivesse suportada pela linguagem. E naturalmente, na relação analítica, pela transferência.

8. S. Freud (1919). "O sinistro". ESB, vol. XVII. Op. cit.

9. J. Laplanche. La révolution copernicienne inachevée - Travaux 1967-1992. Paris: Aubier, 1992. 


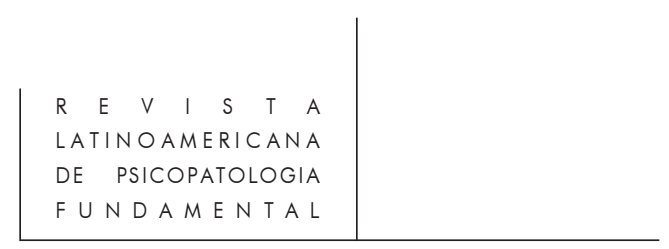

O chiste no estágio inicial, diz Freud, como jogo com as palavras e pensamentos, prescinde de uma pessoa como objeto. Mas já no estágio preliminar de gracejo, se se consegue salvar o jogo e o nonsense dos protestos da razão, isso requer uma outra pessoa a quem se possa comunicar o resultado. Freud acaba por parafrasear Shakespeare, "A fortuna de um gracejo reside no ouvido - De quem o escuta, nunca na língua - De quem o faz..." ${ }^{10}$. De modo que a comunicação de algo do inconsciente do analista é traduzida pelo paciente, o sentido dado à interpretação ocorre também por parte do paciente que a traduz segundo sua conflitiva psíquica uma vez que está imbricado na relação por conta da transferência.

A questão do sentido no nonsense consegue manter o jogo gratificante do chiste e é um esforço para protegê-lo da crítica da razão. Se a elaboração do chiste fracassar o mesmo pode ser rejeitado como nonsense. Citando Freud: "A psicogênese dos chistes nos ensinou que o prazer em um chiste deriva do jogo com as palavras ou da liberação do nonsense e que o significado nos chistes pretende simplesmente proteger o prazer contra sua supressão pela crítica" ${ }^{11}$.

O nonsense destina-se a servir aos mesmos objetivos da representação. Uma fachada sem sentido é adequada particularmente para aumentar a despesa psíquica do ouvinte, aumentando assim a cota liberada por meio da descarga pelo riso. Há um sentido por trás dessa chistosa falta de sentido do nonsense, e tal sentido é o responsável pela conversão do nonsense em chiste.

Freud relaciona algumas características dos chistes que indicam a origem desses no inconsciente. A primeira delas seria o fato do chiste ocorrer como que "involuntariamente". Não acontece de sabermos, um momento antes, que chiste faremos. Necessitamos apenas "vesti-los em palavras"12. Os chistes com freqüência não estão disponíveis em nossa memória quando precisamos deles, aparecem, muitas vezes, em pontos no nosso curso de pensamentos em que não parecem ter relevância alguma.

O riso naturalmente tem um fator de relevância na concepção do chiste, ele é por sua vez indicativo da aproximação realizada do inconsciente; como diz Freud, "muitos de meus pacientes neuróticos, sob tratamento analítico, demonstram regularmente o hábito de confirmar algum fato pelo riso quando consigo dar-lhes um quadro fiel de seu inconsciente, ocultado à percepção consciente; riem mesmo quando o conteúdo desvelado não justifica absolutamente o riso. Tal fato sujeitase, naturalmente, a uma aproximação do material inconsciente, íntima bastante para captá-lo, depois que o médico o detecta e o apresenta a eles"13.

10. S. Freud (1905). Op. cit., p.139.

11. Id., ibid., p. 127.

12. Id., ibid., p. 158.

13. Ib., ibid., p. 160. 


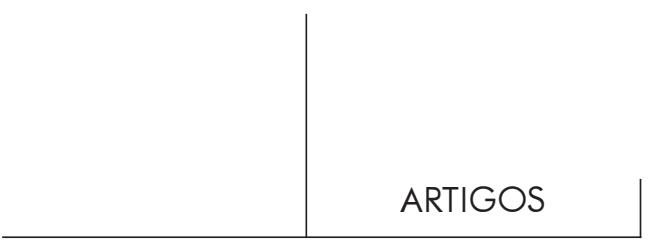

Basicamente, está aí a metapsicologia do chiste. Ri-se com o chiste porque, apesar de desejá-lo, não se pode bolinar ou agredir alguém diretamente, ri-se porque algo tornou permitido ao menos manifestar a intenção de fazer o que não se pode.

Outro aspecto interessante a ser salientado a respeito do chiste é o de que ele apresenta uma espécie de dupla face ao ouvinte, forçando-o a adotar dois pontos de vista diferentes em relação ao sentido do chiste. Em um chiste de nonsense; como diria Freud, uma concepção, que leva em consideração a expressão verbal, considera-o como nonsense; a outra, que acompanha as insinuações fornecidas, passa pelo inconsciente do ouvinte e descobre-lhe um excelente sentido. Essa versatilidade do chiste é que lhe empresta um efeito plástico muito útil na modificação da posição subjetiva do ato analítico.

É interessante notar que existe uma diversidade muito grande na técnica dos chistes. Pode-se deduzir que a riqueza do material lingüístico e suas possibilidades de jogo constituem material fértil para as técnicas dos chistes. E que a insuficiência de Freud em tentar categorizá-los em classes únicas e separadas remonta sempre ao fracasso. Do chiste sempre sobra algo. O chiste sempre remete a este momento no qual a palavra não dá conta de referir a tudo o que pode ser dito. $\mathrm{O}$ chiste remete a algo da ordem do indizível, mas não porque não há palavras para descrevê-lo, e sim porque a palavra não o esgota. De tudo o que pode ser dito ainda fica sobrando algo. Fica a pergunta de como se pensar a clínica psicanalítica a partir disso?

\section{Retomando o caso clínico}

No contato com Carlos, todas as minhas tentativas de interpretar o que se passava em nossa relação, após eu ter fechado as portas da sala de atendimento em seguidas sessões, não pareciam surtir nenhum efeito sobre ele. Eu ficava sempre com a sensação de que a necessidade de fechar a porta era somente minha e não conseguia fazê-lo participar disso. Quando a colocação “já entraram todos?” me ocorreu, o que eu pude observar foi que consegui implicar Carlos em uma relação analítica comigo, consegui que ele se desse conta de que também seu inconsciente estava em jogo naquela situação. Que se a porta aberta me colocava questões para pensar, também a ele elas eram colocadas. Se não eram as mesmas que as minhas - e, naturalmente, não eram -, a sua subjetividade só pôde aparecer quando ele se sentiu fazendo parte do que se passava em nossa relação. Entendo com isso também que Carlos me mostrava que se eu quisesse ajudá-lo analiticamente teria de participar num corpo a corpo com ele, pois precisava sentir que eu estava inteira ali, sem me proteger atrás de questões teóricas e/ou técnicas, para que pudesse estar ali também. Embora ele me contar que só poderia vir em pedaços, naquele momento específico por meio dos fragmentos de imagens de seu pai que eu podia ver na sala de espera, 


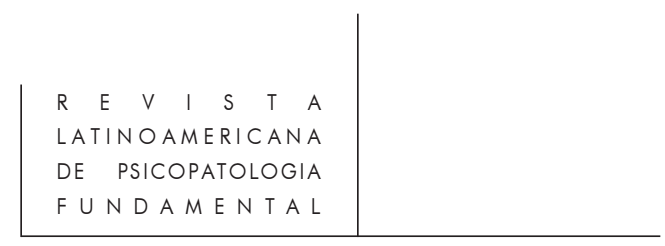

ou que antes apareciam na minha preocupação de que seu pai ouviria nossa conversa.

Desse corpo a corpo, meu e de Carlos, nasce o meu pensar teórico sobre o que se passava conosco. Penso que a interpretação não consegue esgotar a idéia de ato analítico e o chiste é utilizado para demonstrar isso. O chiste nos remete à plurissignificação da palavra. É imediato, espontâneo, surpreendente e não premeditado, é uma espécie de precipitação. Introduz uma destruição uma vez que quebra a estrutura cristalizada do paciente ao mesmo tempo que é também uma abertura. Traz justamente a idéia do que resta do inconsciente, do que não pode ser lembrado, mas nem por isso deixa de estar lá. O chiste nos remete ao que sobra, ao que não pôde ser simbolizado pelo psiquismo, ao resto do enigma que jamais poderá ser resolvido. O chiste de um certo modo reedita este enigma tendo uma relação muito próxima com a situação analítica na qual também a transferência reedita este enigma na figura do analista.

O chiste ancorado na transferência, portanto, empresta seu efeito de desconcerto e esclarecimento à vivência emocional do paciente. A lógica do senso comum tem como objetivo suprimir o equívoco da linguagem ordinária. O resultado disso é uma escrita que não pode ser falada. Falar é produzir equívocos, cadeias significantes que implicam necessariamente um mal-entendido

É interessante notar que para Lacan ${ }^{14} \mathrm{o}$ chiste é a metáfora de uma verdade que se disfarça e que recebe do Outro a sanção que a funda como tal. Se pensarmos que no decorrer do discurso intencional, consciente, do sujeito se produz algo que transcende o querer do sujeito, Lacan diria, acidente, paradoxo, mas também criação, há significantes que se chocam e criam um sentido. Aí se localiza precisamente o chiste. Ele acaba por expor a situação do sujeito. E o torna figura de extremo interesse para uma aproximação com as questões teóricas e clínicas do ato analítico. A idéia é encontrar a dimensão de chiste do ato analítico.

O chiste é um desarrazoado voluntário, um despropósito que estabelece uma ligação entre elementos habitualmente desunidos, inverte deliberadamente uma relação entre fatos, valores ou proposições, exagera uma realidade existente até o paradoxo ou ao insólito, coloca problemas e métodos contrários ao bom senso ou à lógica, consegue ampliar a significação cristalizada que o paciente tem sobre si mesmo e seu inconsciente. $\mathrm{O}$ chiste introduz o mal-entendido.

É essa dimensão que é interessante para se ampliar a idéia de ato analítico, uma vez que também esse pode operar de modo que quebre um funcionamento psíquico rígido e cristalizado. O estudo da estrutura do chiste torna-se, então, um instrumento extremamente eficiente para, por meio da interpretação, ampliar a concepção de ato analítico. O chiste não supõe a leitura de um sentido oculto, mas 


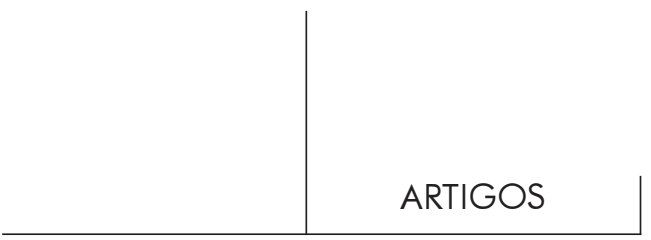

sim a produção de sentido a partir de uma cadeia inapreensível enquanto tal. O chiste coloca como manifesto o mal-entendido e de nenhum modo tenta domesticá-lo.

Talvez se possa pensar que uma verdade comum à experiência lingüística e à experiência freudiana é a de que seria impossível obter uma mensagem a partir de um sujeito qualquer, se não existisse uma cadeia significante e uma rede de seus usos $^{15}$. É a existência desse mecanismo complexo que faz com que um discurso diga sempre mais do que o que quer dizer. É sobre a linha da mensagem ao código e do retorno à mensagem em que pode operar-se a criação de sentido, dimensão essencial à qual nos introduz de cara o chiste. $\mathrm{O}$ chiste como um ato de sentido. $\mathrm{E}$ é na relação transferencial com o analista que o chiste pode emprestar essa dimensão de relâmpago, de precipitação ao ato analítico, ampliando sua gama de ação, criando uma abertura para o inconsciente do paciente. $\mathrm{O}$ chiste transmite uma idéia que circula entre seus participantes, o ouvinte a quem o chiste é transmitido, o falante que faz o chiste, se assim a coisa não se der, se o chiste não for compreendido pelo paciente ou apontado pelo analista, ele não tem valor em si mesmo.

Lacan ${ }^{16}$ intui algo interessante sobre a análise da transferência na sua dimensão interpretativa, a intervenção do analista funciona porque atua sobre uma cadeia significante, seu efeito não diz respeito a um elemento isolado dessa cadeia, mas sim a sua articulação. Ele se pergunta se é sobre uma organização do inconsciente estruturado como uma linguagem que a interpretação vem a se aplicar.

Quando buscamos compreender a estrutura do ato analítico apoiados nas hipóteses freudianas a respeito do funcionamento inconsciente e ancorados pela prática clínica, observamos que o chiste funciona como uma espécie de tropeço incerto em que o analista atinge algo do paciente sem sabê-lo, atinge algo que talvez esteja fora dessa cadeia significante. Isso se passa assim talvez pela homologia estrutural entre algumas formas do ato analítico e o chiste.

Esse tropeço onde o analista atinge algo do paciente sem o saber e passa a sabê-lo imediatamente com as notícias que recebe do inconsciente do paciente por meio do chiste, permite-nos pensar o ato psicanalítico como uma abertura na relação transferencial. Introdução ou aparecimento que vai se reeditando ao longo do processo psicanalítico e que é facilitado pelo chiste, entre outros elementos. O chiste funciona como um agente catalisador por ser justamente um elemento da formação do inconsciente. É o chiste e não outro elemento dessa formação que se adapta a essa aproximação justamente por essa homologia estrutural com o ato analítico.

Para finalizar essas considerações nada melhor do que nos lembrarmos de uma nota de rodapé em que Freud cita Mélinand “ce qui fait rire c'est ce qui est à la

15. E. Carbajal; R. D’Angelo e A. Marchilli. Una introducción a Lacan. Buenos Aires: Lugar Editorial, 1984.

16. J. Lacan. (1967-68). "O ato analítico". 


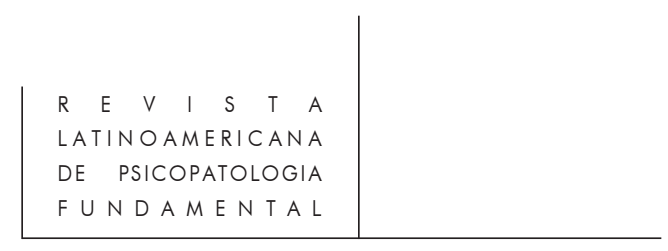

fois, d'un côté, absurde et de l'autre, familier"17. Por meio do riso, de uma forma um tanto quanto peculiar, e talvez se possa dizer absurda e familiar, Carlos adentra a análise por meu intermédio, uma estranha entre sinistra e familiar, e por meio dele próprio.

\section{Resumos}

El artículo utiliza el dicho espiritoso de Freud para reflejar sobre algunas cuestiones del acto analítico. El ejemplo clínico presentado sirve a una ilustración práctica de una posíble estructura chistosa del acto analíctico.

De forma sintética presentase los puntos de interés de la comprensión freudiana sobre los chistes para una aproximación de la noción de acto analítico. El caso clínico es reanudado con la intención de funcionar como una especie de línea, que costura los aportes teóricos presentados a lo largo del texto. Lacan es mencionado para ampliar la visión lobre los chistes e incluir la noción de chiste como un acto de sentido.

Palabras llave: Psicoanálisis, chiste, acto analítico, transferencia

L'article se serve de le dit spirituel de Freud pour réfléchir sur quelques questions au acte analytique. L'exemple clinique présentée se prête a une illustration pratique de une possible structure spirituel au acte analytique.

De façon synthétique, on discute les points d'interesse de la compréhension freudiénne sur les plaisanteries[chistes] pour une approximation de la notion de acte analytique. Le cas clinique est repris, avec l'intention de fonctionner comme une sorte de ligne, qui va cousant les théories présentée dans le texte. Lacan est mentionnée dans le sens d'élargir la perspective sur les plaisenteries et inclure la notion de plaisenterie comme un acte de sens.

Mots cles: Psychanalyse, plaisanteries (chistes), acte analytique, transference

This article uses the Freud's theoretical approach on the jokes to think over some questions related to the analytical act. The clinical example here presented is a useful illustration of a sort of joking structure that would be in progress in this act.

In a synthetic way, we discuss the interesting points about the freudian understanding of the joke in order to deal with this conceptualization of the so-called analytical act. The clinical case is retaken in order to bring up a sort of thread that sews the theoretical approaches presented throughout the text. Lacan is mentioned so that we can both enlarge our view about the joke issue and take this notion as an act of will.

Key words: Psychoanalysis, joke, analytical act, transference

17. "o que faz rir é o que é, por um lado, absurdo e por outro, familiar". S. Freud (1905). Op. cit., p. 218. 